\title{
10 ERRORES FRECUENTES AL HABLAR DE EDUCACIÓN ARTÍSTICA. APUNTES PARA FUNDAMENTAR IDEAS Y DESESTIMAR ESTEREOTIPOS
}

\author{
Recepción: 16/07/2020 | Revisión: 18/08/2020 | Aceptación: 23/08/2020
}

\author{
Josep GUSTEMS \\ Universitat de Barcelona \\ jgustems@ub.edu
}

\section{Diego CALDERÓN}

Serra Hunter Fellow, Universitat de Barcelona dcalderon@ub.edu

\section{Sílvia BURSET}

Universitat de Barcelona

sburset@ub.edu

\section{Carolina MARTÍN}

Universitat de Barcelona carolinamartin@ub.edu

\begin{abstract}
Resumen: Este artículo trata de analizar, a partir de documentos y literatura científica, algunas consideraciones sobre la educación artística que podrían llevarnos a errores fundamentados en estereotipos superficiales. Para ello se repasan investigaciones sobre cuestiones históricas y curriculares vinculadas a la implementación de los estudios de maestros especialistas en artes, tanto de primaria como de secundaria, centrándonos especialmente en el contexto español y europeo. También se examinan algunas relaciones de la educación artística con la educación emocional, los límites de la interdisciplinariedad aplicada a educación artística y las políticas académicas respecto a la formación de maestros especialistas en España. La presencia universitaria de estas áreas de conocimiento conlleva algunos impedimentos de orden histórico, formativo y organizativo que pueden representar una dificultad añadida a la consolidación de dichas áreas. Todo ello nos permitirá hacer un repaso de los contenidos, procesos y decisiones educativas inherentes a estas materias, pues forman parte de su idiosincrasia y epistemología. Como conclusión, se destaca la necesidad de romper con algunos estereotipos que dificultan el avance y la consolidación de estas áreas por parte de la comunidad educativa a todos los niveles.
\end{abstract}

Palabras clave: educación artística; educación musical; educación visual y plástica; formación de maestros; profesores especialistas.

\section{FREQUENT MISTAKES WHEN TALKING ABOUT ARTISTIC EDUCATION. NOTESTO GROUND IDEAS AND DISMISS STEREOTYPES}

Abstract: This paper aims to analyze some considerations
about artistic education that could lead us to mistakes based
on superficial stereotypes. For this, a research review is present-
ed of historical and curricular issues related to the implemen-
tation of the studies of specialist teachers in arts, both primary
and secondary, especially focused on the Spanish and European
context. Some relationships between arts education and emo-
tional education are examined, and so are the limits of inter-
disciplinarity applied to arts education, and academic policies
regarding the training of specialist teachers in our country. The
presence of these areas of knowledge in higher education entails
some impediments of a historical, formative and organization-
al nature that may represent an added difficulty to their con-
solidation. All this will allow us to review the content, processes
and educational decisions inherent to these subjects as part of
their idiosyncrasy and epistemology. We conclude there is a
need to break some stereotypes that hinder the development
and consolidation of these areas by the educational community
at all levels.

Keywords: arts education; music education; visual education; teacher training; specialist teachers.
10 ERRORS FREQÜENTS OUAN PARLEM D'EDUCACIÓ ARTÍSTICA. APUNTS PER FONAMENTAR IDEES I DESESTIMAR ESTEREOTIPS

Resum: Aquest article tracta d'analitzar, a partir de documents i literatura científica, algunes consideracions sobre leducació artística que podrien conduir-nos a errors fonamentats en estereotips superficials. Per això repassem investigacions sobre qüestions històriques $i$ curriculars vinculades a la implementació dels estudis de mestres especialistes en arts, tant de primària com de secundària, centrant-nos especialment en el context espanyol $i$ europeu. També s'examinen algunes relacions de leducació artística amb l’educació emocional, els límits de la interdisciplinarietat a plicada a leducació artística i les polítiques acadèmiques referents a la formació de mestres especialistes a Espanya. La presència universitària d'aquestes àrees de coneixement comporta alguns impediments dordre històric, formatiu i organitzatiu que poden representar una dificultat afegida a la consolidació d’aquestes àrees. Tot això ens permetrà fer un repàs dels continguts, processos $i$ decisions educatives inherents a aquestes matèries, ja que formen part de la seva idiosincràsia i epistemologia. Com a conclusió, es destaca la necessitat de trencar amb alguns estereotips que dificulten lavenç i la consolidació d'aquestes àrees per part de la comunitat educativa a tots els nivells.

Paraules clau: educació artística; educació musical; educació visual i plástica; formació de mestre; professors especialistes. 


\section{Introducción: ¿por qué 10 errores?}

El Congreso Internacional sobre el Papel y el Lugar de la Música en la Educación de Jóvenes y Adultos, convocado por la Unesco en 1953, marcaría un antes y un después en la consideración curricular de la Educación Musical y su presencia en la educación. El camino seguido desde entonces no ha sido unívoco ni homogéneo en todo el mundo y ha dependido en gran medida de las voluntades políticas, tendencias culturales, inercias institucionales y en última instancia, de las cualidades humanas, pedagógicas y profesionales de cada educador (Unesco, 1998).

Años más tarde, en Lisboa, este organismo reconocía que en muchos países las políticas educativas concedían escaso valor a la educación artística, lo cual se refleja en el aislamiento y la devaluación de este ámbito del conocimiento (Unesco, 2006). En el extremo «superior» encontraríamos iniciativas para dignificar y salvaguardar la educación musical y artística en las escuelas y la formación de especialistas correspondientes, como en Suiza (López y De Moya, 2017). Pero no todos estamos en el extremo superior de la curva: las políticas educativas de algunos países europeos parecen aprovechar cualquier oportunidad para contrarrestar las expectativas generadas hace décadas con la inclusión de la educación artística en la escuela.

La música es una de las materias que ejerce mayor influencia en el ser humano, ya sea por sus efectos emocionales, cognitivos o sociales. Pero, ni aún así la investigación aplicada parece que resuelva los principales retos con que se encuentra el profesorado de estas áreas, ni las revistas especializadas llegan a colmar tantos interrogantes en unas didácticas a las que se exige un cuerpo de conocimiento que no alcanzan a obtener... Y es aquí donde aparecen los 10 errores.

Se trata de ideas, estereotipos, ficciones, ilusiones, bulos, que vienen a sustituir a modo de una determinada fe y una experiencia trascendental aquello que debería ser ciencia y conocimiento aplicado. La mayoría parten de una buena intención, mayúscula en muchos casos, pero que no contribuye a fijar buenas prácticas ni un posicionamiento claro y delimitado en el contexto educativo actual.

El objetivo de este trabajo es, pues, analizar, a partir de documentos y literatura científica algunas consideraciones sobre la educación artística que, aunque bienintencionadas, podrían llevarnos a error, guiarnos por un laberinto circular en el que daríamos vueltas sin ver nunca una salida. Todo ello nos permitirá hacer un repaso de los contenidos, procesos y decisiones educativas inherentes a la educación artística, pues forman parte de su idiosincrasia y epistemología.

\section{En la escuela no hay tiempo para aprender tantas cosas}

En la actualidad asistimos a cierto declive de las materias artísticas en la enseñanza obligatoria (Primaria y Secundaria), frente al predominio de materias «científico-instrumentales»-STEM (Aróstegui, 2016). La educación artística no está considerada como otras disciplinas, cuyo objetivo es promover futuras carreras que contribuyan a la mejora de la calidad de vida física de los ciudadanos (Bernabé y Cremades, 2017). Informes de tinte cuantitativo, como PISA o las Competencias Básicas, intentan establecer un estándar centrado en las asignaturas «fuertes», dejando de lado otros aspectos formativos, como el arte, desoyendo de algún modo las conclusiones e indica- 
ciones del Consejo de Europa a favor del papel de la música, la cultura, los artistas o la educación artística (López y De Moya, 2017).

Algunos indicios de dicho declive giran en torno al hecho de que, en la mayoría de los sistemas educativos del mundo, las clases de arte (música y visual y plàstica) no proporcionan el nivel de recursos necesario para una instrucción efectiva (Aróstegui, 2016). El escaso número de horas, las reducciones presupuestarias, junto a una formación muy diversificada del profesorado hacen que el currículo artístico obligatorio sea tan flexible que, en ocasiones no sea homologable. Además, el rol que las artes podrían jugar en el desarrollo de ciudadanos activos ya no es reconocido o apreciado. Los signos de declive de la presencia de las artes en la educación parecen irreconciliables con los desarrollos sociales y tecnológicos contemporáneos, enfocados a la «economía del conocimiento». Así las cosas, el arte aparece como un recurso educativo para entretener, o una oportunidad de ascenso social para los muy pobres con mucho talento artístico, o una referencia para señalar estatus y cultura en las clases altas.

Frente al «no hay tiempo para aprender tantas cosas», encontramos los trabajos pioneros de Spychiger et al. (1993) y de Zulauf (1993), realizados en escuelas suizas, demostrando que aumentar las horas de música en el aula no tendría un efecto perjudicial en el nivel de lenguaje y de lectura, a pesar de la reducción temporal de estas materias, lográndose una mejora en la cohesión y ajuste social en la clase, una mayor autosuficiencia y actitudes más positivas en los niños. Desde entonces hemos asistido a numerosos trabajos que intentan demostrar y profundizar en los efectos de la música y el arte en la escuela: efectos intelectuales, sociales, motivacionales, creativos o de pensamiento crítico (Kokotsaki y Hallam, 2011).

En este sentido, la Comisión de Cultura y Educación del Parlamento Europeo, en 2008, planteó que la enseñanza artística fuese considerada universalmente como un componente indispensable de la educación, garantizando que sea asignatura obligatoria en todos los sistemas educativos, con el objetivo de ayudar a descubrir la diversidad de expresiones culturales, desarrollar su sensibilidad hacia éstas, contribuir a descubrir el placer por el arte y la cultura, reforzar las identidades y valores, y proteger la diversidad cultural.

Es deplorable que, por imperativos economicistas, los estados se vean impelidos a reducir el tiempo destinado a las artes en la educación. La educación artística es un desafío fundamental que deben asumir los países y un componente esencial en la formación de los niños y jóvenes. A pesar de que existan importantes disparidades entre los modelos de enseñanza artística de distintos países, esta debería ser un elemento obligado en los programas educativos, pues conlleva intrínsecamente una aspiración de educación ciudadana y participa en la configuración de las ideas y la realización personal en el plano intelectual, afectivo y corporal, siendo un auténtico reto educativo en nuestra sociedad actual (Gustems et al., 2018).

\section{La educación artística es básicamente educación emocional}

Estas últimas décadas hemos asistido a un crecimiento exponencial del interés por la educación emocional. A partir de la Teoría de las Inteligencias Múltiples de Gardner (1983), apareció la ne- 
cesidad de explicar la implicación de los aspectos emocionales y motivacionales en el desarrollo competencial. Trabajos pioneros como los de Goleman (1995), ayudan a entender mejor el papel fundamental de las emociones en los aprendizajes. Además el uso de recursos artísticos de todo tipo en la búsqueda del bienestar a través de la corriente de pensamiento New Age han provocado una cierta confusión en el uso emocional de las artes, como si se tratase de una única cosa. La profusión de terapias alternativas en busca del bienestar, resiliencia y positividad han difundido muchas de sus técnicas, aunque con el peligro de generalizar, exagerar y confundir cualquier potencial beneficio. En este sentido, además, también proliferaron los discursos vacíos de contenido o con un conocimiento muy limitado sobre la relación evidente entre emoción y arte.

La educación artística innegablemente genera efectos en la educación emocional de las personas, aunque estos vendrán condicionados por el tipo de arte (visual, escénico, sonoro...), por la forma de aplicación (pasiva, activa), y por las consideraciones sociales atribuidas en cada momento (modas, novedad, soporte...). En este sentido algunos trabajos tratan de dilucidar y distinguir los efectos emocionales de las artes, como por ejemplo el de Calderón et al. (2020), que analizan las emociones generalmente provocadas por cada arte (ver Figura 1).

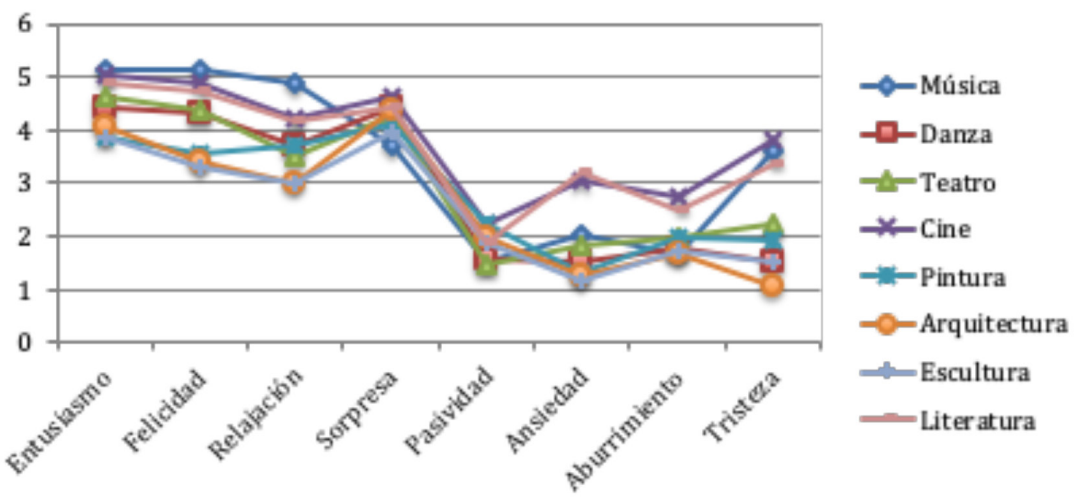

Figura 1. Emociones provocadas por cada arte. Fuente: Calderón et al. (2020)

Los resultados obtenidos nos obligan a pensar que debemos seleccionar qué arte resulta más apropiado en cada situación y ser prudentes a la hora de decidir sobre los efectos que provocaremos en el alumnado y en el profesorado. Pero por encima de todo, hemos de tener en cuenta que existen otros contenidos en la experiencia artística, además del emocional: sociales, técnicos específicos de cada arte (sonoros, perceptivos, visuales, manuales, instrumentales), comunicativos, simbólicos, actitudinales, históricos, políticos, del trabajo en equipo, del liderazgo, periodístico, económico, y un largo etc.

La experiencia artística es emocional, provoca emociones, pero en eso no se diferencia demasiado de la inquietud científica, del deseo de descubrimiento que comparten el resto de materias, de la literatura, la ciencia, el deporte, el teatro, la danza o las ciencias naturales. Por lo tanto, asignar la educación emocional a la clase de educación artística es desatender el contenido motivacional del resto de materias del currículo, algo que no puede ni debería suceder. Integrar 
las artes y las emociones artísticas al resto de materias podría ser un buen punto de partida para mejorar el aprendizaje de materias arduas, como las matemáticas que podrían aprovechar juegos, soportes visuales, materiales manipulativos, canciones, colores, y todo tipo de recursos para hacer de la educación científica un lugar más habitable, más humano.

Bajo esta perspectiva, coincidimos con Willems (1989) en que los profesores de artes seguimos siendo unos privilegiados. No obstante, cabe decir que los procesos artísticos por sí mismos también contribuyen al desarrolloro del sentido crítico, la reflexión, la iniciciativa, la planificación, la argumentación y otras acciones vinculadas al «intelecto». Cuando hablamos de procesos artísticos, estamos aludiendo a formas de pensar y actuar en la que las personas aprendemos en el propio proceso de creación gracias a la conjugación de contenidos, tanto conceptuales como procedimentales, en el camino de dar sentido y formalizar una idea.

Desde una pedagogia competencial, el ámbito artístico puede trabajarse por, desde y con los otros ámbitos de las competencias básicas. Entre otros, podemos citar el proyecto que Anne Bamford desarrolló en el año 2009 por encargo de la Unesco y en colaboración con el Australia Council for the Arts y la International Federation of Art Councils and Cultures Agencies para constatar que los programas de educación artística contribuyen de manera clara a la atención y la concentración de los estudiantes.

En lo que respecta a la docencia vinculada al desarrollo de las competencias artísticas, es necesario que los docentes implicados se sitúen en un paradigma en el que tengan claro que trabajar con el arte y desde el arte va más allá de pintar, cantar, bailar, tocar un instrumento o actuar en un escenario. No se puede centrar la mirada únicamente en las evidencias finales y objetos, sino que también hay que atender a los procesos generados por los sujetos (Burset, 2020).

En este sentido, tomando el caso de las artes visuales, tal y como dice Marín (2003), la Educación Artística no debe reproduir sino por el contrario desactivar los prejuicios habituales sobre el arte en nuestra sociedad porque los estudiantes normalment adoptan y reproducen actitudes mayoritariamente establecidas para cada tipo de conocimiento; por ejemplo, «las matemáticas son difíciles», «el arte moderno es incomprensible y es una tomadura de pelo». Por lo tanto, se hace preciso trabajr en propuestas que avloren positivamente los esfuerzos creativos por descubrir nuevas imágenes, formas y conceptos visuales.

\section{La educación artística lo arreglará todo}

Por desgracia, el «efecto Mozart» ha hecho mucho daño. Pensar que una materia, sea cual sea, pueda ser la solución a los déficits sociales, intelectuales o psicomotores de un alumno, resulta un reduccionismo inútil y evidentemente nos lleva a una situación paradójica: ¿son los artistas y músicos personas mejor integradas socialmente, más listas, más habilidosas? Pues no siempre. La realidad nos enfrenta a la falacia de pensar que con más artes visuales o música los problemas escolares se acabarían.

A pesar de este posicionamiento, no debemos pasar por alto que las experiencias educativas centradas en la música aportan componentes altamente interesantes. Kokotsaki y Hallam 
(2011) describen los beneficios cognitivos y sociales que reciben los estudiantes de música. Gustems et al. (2016) revisan las principales investigaciones en el ámbito cognitivo musical de las tres últimas décadas, y a su vez, Carrillo, Viladot y Pérez (2017) presentan las principales investigaciones dentro y fuera de las aportaciones en el ámbito de la propia música. Estudios sobre compromiso, autoestima, bienestar, trabajo en equipo, sensibilidad, autodisciplina, coordinación motriz, memoria, creatividad, inclusión, convivencia escolar, cooperación, pensamiento crítico... son temas que han sido tratados en investigaciones centradas en todo tipo de participantes: niños, jóvenes, adultos, ancianos, músicos profesionales, estudiantes, y aficionados. Durante años, las revistas especializadas así como proyectos internacionales se han ocupado de forma intensiva en publicitar al máximo todo tipo de resultados para intentar convencer a los políticos de la conveniencia de la inclusión de la música y las artes en los currículos obligatorios, aunque no siempre con éxito. Parece como si tales logros pudiesen conseguirse desde otras áreas, y por eso es cuestión de elección la inclusión en mayor o menor medida de artes y música en la educación.

La educación artística no lo arreglará todo, pero quien haya tenido alguna experiencia artística nunca dudará de sus efectos sobre la auto disciplina, la creatividad, el respeto por el trabajo de los demás, y la expresión sintética dentro de un entorno que necesariamente debe salvaguardar la ética más básica (Gardner, 2008). Desde la pedagogía hemos de plantear alternativas que permitan recuperar o inventar prácticas que respondan a los principios y criterios de un hacer lento, concentrado, sensible, que permita aprender a vivir con una intensidad serena y compartida.

La pedagogía estética nos introduce en una vivencia íntima del espacio y del tiempo de los sujetos que protagonizan la experiencia sensible. Se necesita una pausa, un alejamiento temporal de las demandas inmediatas, ser capaz de detenerse a fin de percibir y, seguidamente, pensar, valorar y emitir juicios sobre las impresiones y aprendizajes recibidos. La formación de la sensibilidad es necesaria para poder desarrollar un programa pedagógico completo que permita el acceso al conocimiento filosófico, ético o espiritual, una convicción ilustrada sobre la fuerza educativa del arte: sólo mediante una mirada atenta y educada en clave poética se podrá aprender a vivir y a actuar plenamente en sociedad (Collelldemont, 2008). La educación artística no lo podrá arreglar todo, pero sin duda es un buen aliado en la mejora de la sociedad y las personas.

\section{Tener maestros especialistas en música y arte nos hace «más europeos"}

O eso pensábamos hace unas décadas... aunque la verdad no resulta tan simple. En los años 60 y 70 del pasado siglo pensábamos que en Europa, a diferencia de nuestra realidad nacional, la música formaba parte de la escolaridad obligatoria. Algunos cursos de verano de metodologías Kodaly u Orff que se impartían en algunos países con gran tradición musical así nos lo hicieron pensar. La realidad, como se encargó de demostrar la tesis de Cateura (1992), era y sigue siendo otra: la música está presente en la educación europea, pero de muy diversas formas, grados e intensidad, una formación específica que, una vez más, tampoco es uniforme en el espacio europeo de educación. 
En este sentido, el informe Eurydice (2010) presenta un completo análisis sobre el estado actual de la Educación Artística y Musical, tanto a nivel nacional como entre estados: modelos de Educación Artística, tipo de docentes, organización curricular, evaluación, número de horas lectivas, y la formación del profesorado de materias artísticas en la educación general obligatoria. El trabajo de López y De Moya (2015) viene a completar dicho análisis, planteando dos posibles modelos curriculares: Educación Artística (que incluye todas las artes), y la posibilidad de separar Artes Visuales de Música. Dichos modelos conllevan distintas figuras docentes; así encontramos muchos países donde la música y las artes son impartidas igual que el resto de materias por maestros generalistas (el caso de Bélgica, Bulgaria, Chipre, Eslovaquia, Estonia, Reino Unido, Rumanía, Francia, Irlanda, Finlandia, Italia, Austria, Chequia o Luxemburgo). El resto de países se divide entre los que tienen especialistas para música (como el caso de España, Grecia, Malta o Lituania), y los que cuentan con especialistas en los cursos más elevados y generalistas en los iniciales (Alemania, Croacia, Eslovenia, Holanda, Hungría, Letonia, Polonia, Portugal y Suecia).

Podemos resumir este mapa en dos polos opuestos que, a priori, son igualmente justificables desde el punto de vista de la educación. La posición pro-generalista asume que la educación es una sola cosa y que el niño es un todo único que se beneficia de la enseñanza en la medida que se le preste atención a su experiencia y se le ayude a progresar adecuadamente. Se necesita alguien que dé sentido a la experiencia global y asegure un desarrollo constante y equilibrado. El maestrogeneralista estaría en una posición ideal para esta función de supervisión educativa, porque se pasa más tiempo con los niños, los conoce mejor y sabe las necesidades de cada uno (Serrano, Lera y Contreras, 2007).

Por el contrario, la posición pro-especialista, asume que cada vez se exige más de los niños $y$ de sus profesores, un incremento del conocimiento y habilidades y no puede esperarse que ningún maestro pueda razonablemente saber y enseñar todo lo que le es requerido, todas las materias del currículum escolar en varios niveles simultáneamente. La solución más obvia sería que no fuera un solo maestro quien asuma las responsabilidades educativas del niño y que sean más de uno los maestros que asuman responsabilidades acordes a su especialización.

Ante este panorama tan complejo y cambiante, lo que asegurará la calidad de la docencia artística será la formación que reciban los docentes, así como las condiciones de dicha docencia, especialmente en lo que respecta al número de horas (Bernabé y Cremades, 2017). En España, las universidades ganaron el debate a los conservatorios y escuelas de arte, prefiriendo «maestrosmúsicos» a «músicos-maestros», es decir, que ante la posibilidad de articular un título compartido en ambos tipos de centro, se prefirió priorizar la formación humanístico-social-pedagógica propia de las universidades, abriendo las puertas a estudiantes de contaban con una formación musical previa realizada durante la primaria o la secundaria y permitirles una formación para ser maestros, a la vez que se les daba un espacio para el arte o la música. Posteriormente, con la llegada de los grados, esto derivó en las menciones, donde junto a la educación musical también encontramos la plástica y visual.

Proporcionar una educación artística de calidad es el único modo de garantizar su continuidad y su desarrollo (Holden y Button, 2006). A su vez, la consideración de los maestros dedi- 
cados a esta área dependerá en buena parte de la opinión de sus iguales, así como de los maestros que requieran de su supervisión y asesoramiento -como podrían ser el profesorado de educación infantil, que debería ser competente en todas las áreas del currículo, pero que se apoya gratamente en profesores especialistas, más capacitados en las especialidades respectivas-. Incluso estos autores recalcan que la mejor apreciación de las artes por parte de los alumnos se da cuando ambos profesores trabajan e imparten conjuntamente dichas materias.

Naturalmente una organización de ese estilo conlleva dificultades económicas y organizativas. Desde hace años, algunas instituciones de educación artística tienen convenios con escuelas de primaria y secundaria (inspirándose en las magnet schools) para enviar profesorado artista a las aulas de primaria y secundaria, con el fin de motivar e inspirar procesos creativos y trabajar con el profesorado especialista y generalista de dichos centros. Dichas iniciativas suelen estar sujetas a la financiación de Ayuntamientos y hasta ahora cuentan con muy buenos resultados, participando centenares de estudiantes y un número elevado de artistas «residentes» (Andrews, 2016).

\section{Si sabes de un arte, sabes de todos}

En relación a algunos otros arquetipos que siguen circulando en distintos contextos relacionados con la educación artística y que mayormente ensombrecen al contexto educativo actual, podemos encontrar el relativo a pensar que el arte es uno, y si es así, que cualquier especialista formado en una de las siete artes puede enseñar y educar en cualquiera de ellas.

Esta consideración, que a primera vista puede parecer muy obvia y que forma parte inherente al conocimiento de las Bellas Artes, parece que en el contexto educativo no está dotada de dicha individualidad. Está claro que una persona educada en un carácter creativo puede serlo en diversas de las artes. Pero pongamos un ejemplo: pensar que una persona dotada de conocimientos y cualidades para la música pueda enseñar plástica, pasando por alto la singularidad y peculiaridad de la disciplina, es como mínimo incoherente. Está claro que el planteamiento nace de una intención práctica de agrupar bajo la denominada «educación artística» aquellas materias escolares que se conectan por el adjetivo artístico, pero ¿acaso bajo esta agrupación, existiría una profunda reflexión de la propia epistemología de las artes? ¿acaso tienen una misma idiosincrasia para valorarlas como algo análogo entre sí?

Revisitar algunas de las teorías sobre la configuración epistemológica de lo artístico, en general puede ayudar al análisis de los conceptos más básicos que nos dan los axiomas para huir de dicha anexión en los contextos escolares, que no coadyuvan a afianzar unas correctas praxis en torno a dichas disciplinas.

Solo es necesario revisar el transitar historiográfico por las muchas corrientes artísticas y su pensamiento acerca de la esencia de lo epistémico respecto a lo artístico para ver las múltiples teorías como la Kantiana, Hegeliana o Marxista (Sanchez, 2013) acerca de la identidad y sustancia del Arte en mayúsculas. Pero antes de ello, debemos tener en cuenta, en palabras de Dubatti (2012), cinco visiones de la doxa (pensamiento no científico) sin fundamentación argumentativa, muy arraigadas en la oralidad y en la escritura del campo artístico, que a su manera dan una 
respuesta a esta «des-definición del arte» y que se explica mediante cinco posturas básicas; nos referimos a: «Todo es arte» o la visión reduccionista que afirma que «Sólo es arte tal tendencia particular» o sólo es arte «lo que hace ese justo grupo de artistas». También encontramos la postura negacionista que postula que «El arte ha muerto» o aquella contraria que asegura que «Arte es cualquier cosa a la que convenga llamar arte» así como la visión más subjetivista que plantea que «en el arte todo es subjetivo» (Dubatti, 2012:149).

Esta travesía, que puede estar relacionada con el pensamiento académico o con los saberes populares, se puede sustentar en diversas fundamentaciones teóricas, pero en nuestro contexto sería necesario poder revisitar aquellas relacionadas con la propia idiosincrasia del término Arte como las planteadas por Popper, Gombrich, y Benjamin que tal y como plantea Sánchez (2013) dimensionarán el valor epistémico del proceso artístico. Pero no será en este texto donde ahondaremos en cuestiones tan complejas así que recuperemos pues la definición más básica que podemos encontrar en la RAE para referirnos al concepto Arte, que se define como «una manifestación de la actividad humana mediante la cual se interpreta lo real y se plasma lo imaginado con recursos plásticos, lingüísticos o sonoros». Así esta sencilla definición ya distingue en tres grandes bloques lo relacionado con lo artístico, podemos entonces pensar que alguien experto en recursos lingüísticos es el adecuado para enseñar algo relacionado con los recursos sonoros o plásticos, pero la lógica responde que no.

Pero podemos ir más allá sin hacer referencia a las palabras de Gombrich (1950) cuando manifiesta que «No hay nada que sea el Arte, tan solo hay artistas» y si fuera así, ¿tendría más sentido? Es decir, ¿acaso no sería más sencillo en lugar de buscar límites claros y definidos en lo artístico, hallar la respuesta en aquellos que ejercitan el saber de lo artístico?, quizás sí que fuera una buena réplica, pero ¿existiría en este caso tantos tipos de enseñantes como de intérpretes o productores de lo artístico? ¿Sería en este caso coherente pensar en ellos como maestros globales de todas las artes? ¿Podríamos creer que cada uno de ellos podría enseñar danza de la misma forma que artes plásticas? Quizás sí que podríamos encontrar algunos pocos casos, pero en el contexto educativo no parece que se encuentren estos perfiles renacentistas que dominan todas las artes con la misma pericia. Así pues, creemos que, desde una visión de la práctica escolar, más cercana a la producción en masa que a la reflexión profunda, es necesario examinar de qué manera determina el especialista, si desde su propia práctica y conocimiento específico o desde su saber más global, aquello más relevante para las aulas y de manera clara.

\section{Facilitaría mucho las cosas que los maestros de artes impar- tiesen música y artes visuales}

La verdad es que, en términos economicistas y organizativos, sería una buena idea para los centros... si no fuese porque en la práctica resultan dos perfiles profesionales muy distintos, con distinta formación, distintas competencias profesionales y personales.

El estudio de la música y el de las artes visuales exigen una alta dedicación, aunque con planteamientos distintos desde sus inicios: las artes visuales destacan por su alto grado de creati- 
vidad y muchas de sus actividades se centran en innovar y aplicar determinadas técnicas a nuevas ideas y contextos, mientras que la música también utiliza la creación y la improvisación, pero en mucha menor intensidad y dependiendo del estilo y el nivel de desarrollo. Por otro lado, la música plantea muchas de sus actividades en equipo, pues mucha de la música que se ejecuta es para conjunto (vocal, instrumental o mixto), por lo que la práctica musical requiere el desarrollo de las competencias sociales, sobre todo saber trabajar en equipo.

Un ejemplo de esta diferencia en las competencias personales aplicadas a la profesión lo encontramos en los estudios sobre fortalezas de carácter llevados a cabo con estudiantes universitarios de música y con estudiantes de artes visuales y plástica. La Tabla 1 muestra las fortalezas más y menos puntuadas, en ambos colectivos, a partir del cuestionario VIA-IS con el que se analizó dicho constructo teórico. Se destacan los ítems especialmente distintos y los coincidentes

\begin{tabular}{|c|c|c|}
\hline $\begin{array}{c}\text { Orden } \\
\text { de Fortalezas }\end{array}$ & $\begin{array}{l}\text { Alumnado de } \\
\text { Educación Musical }\end{array}$ & $\begin{array}{l}\text { Alumnado de } \\
\text { Educación Visual y Plástica }\end{array}$ \\
\hline 1 & Juicio & Creatividad \\
\hline 2 & Amabilidad & Amor \\
\hline 3 & Curiosidad & Juicio \\
\hline 4 & Apreciación de la belleza & Honestidad \\
\hline 5 & Trabajo en equipo & Humor \\
\hline$\cdots$ & & \\
\hline 20 & Amor por aprender & Perseverancia \\
\hline 21 & Perspectiva & Perdón \\
\hline 22 & \multicolumn{2}{|c|}{ Humildad } \\
\hline 23 & \multicolumn{2}{|c|}{ Autorregulación } \\
\hline 24 & \multicolumn{2}{|c|}{ Espiritualidad } \\
\hline
\end{tabular}

Tabla 1. Fortalezas de carácter más y menos puntuadas en estudiantes de música y de artes visuales (a partir de los datos de Calderón et al., 2017; Gustems et al., 2018).

El lugar destacado de la creatividad en los programas de formación y docentes de educación visual no debe extrañarnos; forma parte de la idiosincrasia de estos docentes y de los planes de estudio que desarrollan (Gustems y Calderón, 2013). Más difícil resulta a los músicos seguir con las consignas de utilizar la creatividad como eje estructural de sus clases. A pesar de los intentos y la insistencia de la creatividad en los planes docentes específicos y los derivados de la LOMCE (Bernabé y Cremades, 2017; Prieto, 2001), la enseñanza de la música contiene aún muchos elementos de carácter conservador y «performativo», por delante de los creativos, algo que es común a muchos países de influencia británica.

No obstante, cabe decir que el ámbito de las artes visuales y el ámbito de la música tienen en común un elemento básico como objetivo que es representar la realidad vivida e imaginada, o sea la fantasía, desde el lenguaje no verbal. Tal y como expresa Gómez Molina (2007) cuando nos habla del dibujo, en la medida en que la realidad es inaprensible, en la medida que no es posible 
hablar de la realidad sino de las representaciones que construimos en torno a ella mediante los diferentes lenguajes, los dibujos no representan las cosas, sino que nos hablan de ellas, configuran las imágenes de la realidad desde las representaciones que hemos generado en los diferentes discursos.

La música y las artes visuales tienen formas de expresión propias y se canalizan en diferentes lenguajes, pero las une precisamente el goce estético; entendiendo la estética como el proceso artístico que va más allá de lo bello para dar sentido a los sentimientos, pensamientos e ideas que no solo se expresan, sino que también se van generando en el camino de expresarlas. Las manifestaciones musicales y visuales son formas de representar la realidad, pero también son maneras de entenderla, por ejemplo, desde la metáfora y el símbolo en un contexto determinado.

Una cultura de la innovación permitiría a los docentes de ambas áreas acercar posiciones y establecer como objetivo principal el de contribuir al fomento de la realización personal, la confianza en uno mismo y el desarrollo de la creatividad y el pensamiento innovador (López y De Moya, 2017). Además, el desarrollo del trabajo en equipo -más desarrollado en el profesorado de música- podría establecerse como un dinamizador del trabajo entre especialistas de las dos áreas. Es un camino que explorar.

\section{La educación artística es un área de conocimiento como cual- quier otra}

Con la llegada de la LRU (1983), la Universidad española se organizó en Facultades y Departamentos, encargados de la docencia e investigación en determinados campos de conocimiento que les son propios. Así el ámbito de Educación Artística se estructuró en dos áreas específicas: Didáctica de la Expresión Musical y Didáctica de la Expresión Visual y Plástica, ambas con presencia en las Facultades de Educación (antes Escuelas Universitarias de Formación de Profesorado) y con una dotación de plantilla proporcionada a la de otras áreas según las necesidades docentes. A pesar de ello, existe un retraso histórico en la escasa y tardía presencia de doctores ocupando plazas de profesorado en dichas áreas, lo que ha frenado la investigación y ha colocado a dichas áreas frente a una difícil solución: la necesidad imperiosa de ponerse a la misma altura que el resto de áreas de Educación o Ciencias Sociales, con una plantilla de profesores e investigadores con menor formación respecto a otros campos de conocimiento.

A pesar de ello, el profesorado de dichas áreas ha realizado un gran esfuerzo al tener que buscar recursos para tirar adelante: doctorados, proyectos, revistas y publicaciones de todo tipo. Como comenta Marín Viadel (2011), disponemos de un número suficiente de manuales de investigación, revistas internacionales especializadas, congresos nacionales e internacionales y grupos de investigación como para poder afirmar que desde hace algunas décadas la Educación Artística se configura como un territorio especializado de investigación, con frecuencia conjugando esta dedicación con otras actividades, tanto docentes, como de creación artística (exposiciones, comisariados, conciertos, etc.).

A nivel investigador, los temas y metodologías empleadas en educación artística son com- 
plejos y muchas veces poco comprendidos entre el resto de profesionales de la educación. Los temas, lejos de circunscribirse en ámbitos específicos de la didáctica, con frecuencia atienden a otras miradas cercanas, como la psicología o la sociología, posicionamientos arriesgados, pero que tienen sus propias leyes, métodos y marcos teóricos propios, no siempre conocidos en profundidad. Además hemos de considerar la formación inicial en humanidades (Música o Bellas Artes) de muchos de estos docentes, frente a los requerimientos de las Ciencias Sociales donde se inscriben estas didácticas específicas. Estos hechos, ampliamente corroborados en los trabajos bibliométricos de Gustems y Calderón (2014), Gustems, Calderón y Calderón (2016) y Gustems, Burset y Martín (2018), ponen de manifiesto el carácter abierto, complejo e integrador de tales publicaciones, aunque su falta de especificidad y profundidad les pueda relegar a ser poco leídos y les dificulte producir más artículos. Otra de sus conclusiones es el aislamiento de los autores, que hacen que publiquen en su mayoría un solo trabajo en solitario a lo largo de una década. Esta actitud es totalmente opuesta a la que fomenta el oficio investigador que se nutre de la diversidad de pareceres, de la complementariedad competencial de los miembros de un grupo y de la riqueza que conlleva.

Trabajos como el de Eisner y Day (2004) o el de Pozo, Bautista y Torrado (2008) tratan de ofrecer una panorámica sobre los principales temas de investigación en educación artística, que nos permita trazar líneas futuras de conocimiento y entender cuál podría ser la dinámica de los grupos y proyectos de investigación a nivel internacional. Una revisión de los centenares de comunicaciones presentadas en congresos internacionales de estos campos lo corroboraría. Entre los temas y posicionamientos más presentes suelen encontrarse: capacidades artísticas (talentos...), educación estética vinculada a la filosofía del arte, historia de la Educación Artística (principalmente en el periodo de currículum obligatorio durante los siglos XIX y XX), estudios evolutivos sobre las habilidades y conductas artísticas como espectadores, organización y sistematización del currículum (especialmente en la educación obligatoria), enfoques multiculturales de la educación artística, evaluación del aprendizaje artístico, estándares de calidad, formación inicial y cualificación del profesorado, educación en museos, cultura artística, metodologías artísticas de investigación, diseños basados en la práctica creativa (Practice Based Research), historias de vida, etnografías, motivación, experiencias de «artistas residentes», etc.

El papel del profesor de arte, el del investigador en arte y el del artista deben sintonizarse para ser más efectivos, sabiendo que en la transmisión del conocimiento todos son necesarios, pero cada uno tiene distintas capacidades y entornos donde incidir más adecuadamente. Se necesitan muchas manos y muchas voces, es cierto, pero el futuro dependerá de elegir bien a los protagonistas.

\section{La interdisciplinariedad: la solución mágica}

Muchos no pueden resistirse al hechizo de la interdisciplinariedad, aunque en realidad, en muchos casos se trata más bien de multidisciplinariedad, es decir, actividades donde convergen varias disciplinas que cada una aporta lo suyo, sus técnicas, su metodología, su evaluación, etc. Pocas inicia- 
tivas son realmente interdisciplinarias, pues esto exigiría un tipo de trabajo que no es el que suele darse en las escuelas y en la educación por falta de tiempo, de formación de voluntad y de recursos.

Para entender lo que aporta otro arte hay que conocerlo mínimamente, acercarse a él sin prisas pero con interés, entender sus conceptos „, entender el tejido epistemológico que subyace en su experiencia. Esto no es inmediato, ni fácil, ni automático. Y tampoco muchos pueden alcanzarlo. Además, muchas artes escapan a la interdisciplina.

En el caso de las enseñanzas artísticas que nos ocupan (música y visual), la actividad interdisciplinaria por excelencia es el cine. En él se reúnen íntimamente ambos artes, en un solo producto que depende de la interacción de cada uno de ellos en el otro. Los directores de cine, de alguna manera serían expertos interdisciplinares, pues han de tomar decisiones y promover iniciativas en ambos ámbitos para crear un producto final. Encontramos también otros ejemplos: la canción, la ópera, la danza, el cómic, aunque en general el peso de una de las disciplinas que lo sustentan suele ser superior al resto y los profesionales suelen ser de ese ámbito más que de los otros.

La interdisciplinariedad es una de las soluciones a la debilidad de la educación artística, pero exige una metodología determinada que no siempre es conocida por sus promotores (Piaget, 1979). Dicha metodología plantea el trabajo a partir de «interobjetos» que hay que definir, profundizar y compartir por parte de los docentes. Este sistema de trabajo se da pocas veces en el sistema universitario, acostumbrado a una organización temática muy sectorizada, con poderes definidos y distribuidos, donde la superación de barreras administrativas docentes supone trabas importantes en la profundización de las interdisciplinas. La actual asignación del profesorado a áreas de conocimiento, departamentos y facultades añade un problema más de gestión a la riqueza temática y conceptual de cualquier universidad, que cuenta con muchísimos profesionales expertos pero que no están acostumbrados a trabajar juntos fuera de su zona de confort.

A pesar de las recomendaciones de los currículos oficales, de la European Agenda for Culture-2010, la convención UNESCO en Lisboa-2006 (López y De Moya, 2017) y muchas de las propuestas de los educadores avanzados, la interdisciplinariedad exige la vivencia de experiencias interdisciplinares a lo largo de los años de formación, así como una adecuación metodológica interdisciplinar a los contenidos educativos, algo que no siempre resulta factible ni mucho menos rápido. Solo parte de los contenidos podrán reubicarse en un entorno interdisciplinar. Habrá que elegir cómo proceder entonces, pues la solución no es sencilla.

\section{La formación artística y musical de los maestros y la forma- ción de los maestros en música y artes es adecuada}

¿Se trata del artista que da clases o el profesor que hace arte? O, como describía Abara (2017): ¿artista educador o educador artista? No cabe duda de que navegamos en una estrecha línea que limita un mundo con otro. El rol del artista y el del educador pueden confluir si atendemos a su función social, pero entonces ¿es responsabilidad del arte hacerse cargo de su educación o es responsabilidad de la educación hacerse cargo del arte? Si bien en educación infantil y primaria parece que, y hacemos hincapié en este «parece», la opción más pertinente sería la segunda, trabajare- 
mos desde el supuesto que lo «ideal» es un buen maestro con suficientes conocimientos artísticos.

No vamos a entrar en qué significa conocimientos artísticos, ni en cómo cuantificarlos y acreditarlos cuando el objetivo es desarrollar las competencias asociadas a la educación artística en alumnado menor de 12 años. Pero sí parece interesante reflexionar sobre la similitud entre diseñar y desarrollar un proyecto educativo y uno artístico, la complejidad en su planificación y grado de satisfacción en su logro, el espejo en el que el maestro se refleja como artista y el artista como maestro, y el momento en el que una obra de arte o un proyecto educativo ven la luz (Acaso et al., 2011). Como ya se ha descrito, en el caso de la educación infantil y primaria, lo más habitual y lógico sea encontrar un docente con conocimientos artísticos.

En este punto, retomamos la reunión celebrada por la UNESCO en Lisboa en el año 2006. En ella se apostaba por elaborar programas formativos para los futuros profesores de asignaturas artísticas, de forma que se pudiese fomentar un desarrollo integral conceptual y competencial. Incidiendo para ello en metodologías orientadas a la educación artística y procesos evaluativos adaptados a la idiosincrasia de esta, con una mirada abierta tanto a los ámbitos educativos formales como no formales. En la actualidad, a nivel estatal, esto se articula a través de las menciones. Si bien cada universidad organiza su estructura y funcionamiento, lo habitual es que la mención cuente con una especialización de unos 30 créditos distribuidos en 4-6 asignaturas. En el caso de la Educación Infantil, al no existir la figura del especialista, dicha mención con orientación artística suele ser, salvo algunos casos, más genérica, comprendiendo formación en diferentes disciplinas y con una clara orientación hacia el fomento de la creatividad. Por lo que respecta a la Educación Primaria, sí existe una especialización en Educación Musical y otra en Educación Visual y Plástica.

Ahora bien, si en las Conclusiones del Consejo, de 27 de mayo de 2015, sobre el papel de la Educación Infantil y Primaria en el fomento de la creatividad, la innovación y la competencia digital, se instaba a las diferentes instituciones a tener en cuenta y promover métodos eficaces para fomentar el pensamiento creativo y crítico, la curiosidad, la experimentación y la comprensión cultural, siendo el arte y la música disciplinas básicas para ello (López y De Moya, 2017), la pregunta que nos hacemos parece evidente: ¿son estas 4-6 asignaturas suficientes?

No emitiremos un juicio sobre esto, ya que, obviamente, dependerá del alumnado, sus conocimientos previos y de lo que se considere suficiente. Pero, y para que el lector pueda hacerse una idea, en dichas asignaturas no se debería enseñar las competencias instrumentales relacionadas con la música o la expresión visual y plástica, sino desarrollar las competencias docentes de cada futuro maestro. Esto implica que, en su formación inicial, este debería «venir con los deberes hechos de casa» y haber aprendido lo referido a cada disciplina artística por su cuenta, y en la Universidad se encargaría de la noble misión de enseñar a enseñar. Esto es, en estos momentos, algo más cercano a la utopía que a la realidad. 


\section{La formación de todos los profesores de artes en secundaria es la que debe ser}

Si bien en el apartado anterior hemos partido del supuesto del maestro con conocimientos de arte, en este caso partimos del que podría ser su alter ego: el artista con conocimientos didácticos. En este caso, se trata de una persona que se forma a través de un máster para ser docente de la disciplina que desee. Para ello, según el apartado 4.2 del anexo de la Orden ECI/3858/2007, de 27 de diciembre, publicada en el BOE núm. 312 de 29 de diciembre del 2007, es requisito la acreditación del dominio de las competencias relativas a la especialización que se desee cursar. Es decir, en la Universidad no aprenderá música o artes visuales sino a enseñar música o artes visuales.

Para que el lector se haga una idea de qué significa ese dominio de competencias, en el caso de la música, por ejemplo, un candidato que haya cursado sus estudios superiores ha pasado por cuatro años de enseñanzas de grado elemental, seis de profesional y cuatro de superior. Un total de 14 años en los que ha cursado asignaturas referidas a su instrumento principal, otro secundario, lenguaje musical, armonía, composición, historia de la música, conjuntos instrumentales, y un largo etcétera que le han llevado a tener un conocimiento de la música en general y de su especialidad en particular, con especial énfasis en la interpretación instrumental o vocal. En algunos casos, ha recibido clases de pedagogía en el conservatorio, e incluso ha hecho sus «pinitos docentes» en ámbitos educativos no formales. Pero eso sí, siempre como profesor de música, no de educación musical. Ahí versa la gran diferencia. No podemos considerar igual, y ni siquiera parecido, enseñar un instrumento o teoría musical en una clase individual o de pequeño formato a dar clases en un centro de secundaria, donde ni el temario ni el perfil del alumno es el mismo. Para ello, para transitar del mundo de los escenarios y «la farándula» al aula es necesaria una formación pedagógica rigurosa y de calidad, en especial si pensamos que el docente impartirá su materia a un alumnado adolescente, con lo que ello conlleva.

Si bien lo que acabamos de apuntillar sobre la edad del alumnado puede ser un toque de atención, a esto se une la tradición del Siglo XX del asociacionismo gremial de los profesores de artes (Huerta y Domínguez, 2016), la cual se tambaleó dejando a los docentes en una especie de «tierra de nadie». De esta forma el sentimiento de colectivo desapareció, creándose acciones individuales que no eran suficientes para respaldar el área de la educación artística y educación musical, llegando al extremo de la consideración por parte del Ministro de Educación, José Ignacio Wert de que «la educación artística distrae de las demás asignaturas». Es decir, la educación artística no deja de ser una «asignatura maría» a la que el alumnado, como tal, dedicará los esfuerzos justos, que no necesarios. De esta forma, seguimos sumando, alumnado adolescente que considera, porque así se lo han dicho, poco importante la educación artística.

Si bien esto parece suficiente hándicap, y volviendo a la formación inicial del profesor de secundaria descrita anteriormente, esta se basó en una alta especialización en una corriente musical o artística concreta, sobrevolando el resto en pro de esa preparación cercana a la excelencia. Esto, en la realidad, supone un alejamiento de otros estilos musicales y artísticos más cercanos al consumo de masas y, por ende, a los gustos de los adolescentes (Faure et al, 2020). De esta forma el profesor puede estar, si cabe, aún más alejado del alumnado y de sus motivaciones. 
Recapitulando, el profesor de secundaria, con unos sólidos conocimientos de interpretación musical o producción artística, deberá impartir una asignatura poco valorada a un alumnado adolescente alejado culturalmente, en lo que a gustos estéticos se refiere. Y todo eso deberá hacerlo con una formación docente de un curso académico.

\section{A modo de conclusión, ¿hasta cuándo estos 10 errores?}

Lamentablemente podríamos continuar la lista de errores que en todos los casos hacen referencia a situaciones y acciones entre personas en contextos determinados: estudiantes, docentes, familias, gobernantes, intelectuales, artistas... Nos referimos a todas las posibles personas implicadas, a la ciudadanía que se sustenta en creencias y valores con la riqueza que confiere la pluralidad, la diferencia y la diversidad. Como se ha visto en las pàginas anteriores, resulta necesario romper con determinados estereotipos que dificultan la consolidación y el avance de estas áreas por parte de la comunidad educativa, a todos los niveles. Estos estereotipos guardan relación con aspectos cognitivos, emocionales, sociales, creativos, y son aplicables a muchos niveles educativos, tanto en educación primaria como secundaria y afectan a la formación universitaria de dicho profesorado.

El arte es un camino hacia el conocimiento y éste no se refiere solo a la acumulación de contenidos, conceptos, hechos, definiciones, etcétera sino al amplio espectro que se dibuja en cada persona a la hora de forjar su identidad en el entorno que le rodea y a otros a los que quiere llegar (situaciones), al establecer relaciones (acciones) con estos. Conocer implica pensar y el pensar nos lleva a formas de conocer; en esas formas se encuentra el arte en el amplio sentido de la palabra.

A menudo relacionamos el arte, el hecho artístico, con un resultado, con una melodía, con una pintura, con una obra teatral, etc., sin embargo, desde la mirada pedagógica y didáctica, lo interesante es, precisamente, que aparte de ser una oportunidad para aprender sobre métodos, técnicas, procedimientos, uso de instrumentos o de manipulación de herramientas y materiales, también es, sobre todo, una vía para conocer cómo evidenciar formas de denunciar, de descubrir, de evidenciar, de explorar, de compartir, de crear, de querer, en definitiva... de vivir. Pensar en cómo y por qué esos sujetos (artistas) han creado tales objetos artísticos es precisamente una forma de desarrollar la visión crítica y la opinión argumentada poniendo en juego toda una serie de competencias necesarias para la vida. En ese sentido, Perrenoud (2012) nos recuerda que la educación artística prepara para ciertos componentes de la vida, pero que ello depende de los sistemas educativos y de la concepción del arte que tengan los docentes. A ello hacíamos referencia en el noveno error, cuando aludíamos a la necesidad de la formación del profesorado que no sea solo especialista en el ámbito sino que también tenga una visión holística y global del hecho educativo para así conferir a las artes ese papel importante a la hora de abordar temas de actualidad o temas de siempre, es decir, temas que interesa que interesen.

Hoy en día, tal y como dice Martínez Luna (2017) los cimientos tradicionales sobre los que se sostenía el aprendizaje y sus formas de transmisión están erosionados porque las instituciones educativas se han visto desbordadas por la velocidad de la circulación de la información. Como consecuencia los contextos propicios para saber, conocer, pensar, crear, proyectar, inferir... 
se han multiplicado y diversificado, por ese motivo se hace preciso que el profesorado sea consciente que los procesos educativos van más allá de las disciplinas y que la interdisciplinariedad no debe entenderse como un collage, sino como la combinación de formas de construir, crear y definir diferentes y complementarias. La interdiscipinariedad es una palabra que está muy de moda cuando, paradójicamente, se van desdibujando las disciplinas tradicionales, por eso también es importante delimitar qué entendemos cuando nos referimos a crear situaciones de enseñanzaaprendizaje teniendo presentes diferentes disciplinas a la vez.

Cabe decir que es tarea de los docentes promover en los estudiantes el pensamiento creativo y crítico, la curiosidad, la experimentación y la interpretación de hechos culturales y sociales, pero para ello también es preciso que el profesorado además de tener habilidades comunicativas y de relación, investigue y se impregne de teorías, conceptos y fundamentos del ámbito de la educación artística que vayan más allá de su experiencia personal y emocional. La práctica reflexiva en la docencia requiere un análisis de la labor docente que sea metódico, instrumentado, sereno y efectivo, y con voluntad e intensidad (Domingo y Gómez, 2014). Entre educadores, educandos, artistas y arte anda el juego, pero se hace preciso determinar «reglas» para cuando sea preciso poder transgredirlas en el camino de aprender arte o aprender a través del arte.

Gadamer (2000) dice que la cultura es algo que nos sostiene, pero que ninguno de nosotros sería lo suficientemente sabio como para poder decir lo que es. Pues bien, el arte es una manifestación de la cultura y efectivamente también es difícil definirlo. Quizás su definición esté en su propia indefinición. Educación, arte y personas: este es el gran reto pedagógico.

\section{Referencias bibliográficas}

Abara, J. (2017). ¿Artista educador o educador artista? El límite difuso del rol social. Educación Artística, Revista de Investigación, 8, 24-31. doi: https://doi.org/10.7203/eari.8.9458

Acaso, M., Belver, M. H, Nuere, S., Moreno M. C., Antúnez, N., y Ávila, N. (2011). Didáctica de las artes y la cultura visual. Madrid: Akal.

Alcaraz, M.J., y Pérez, F. (2018). Enciclopedia de la Sociedad Española de Filosofía Analítica. Madrid: Espasa.

Andrews, B. W. (2016). Towards the future: Teachers' vision of professional development in the arts. International Journal of Music Education, 34(4), 391-402. doi: https://doi. org/10.1177/0255761415590361

Aróstegui, J. L. (2016). Exploring the global decline of music education. Arts Education Policy Review, 117(2), 96-103. doi: https://doi.org/10.1080/10632913.2015.1007406

Bernabé, M. M., y Cremades, R. (2017). Sociedad del conocimiento, capital intelectual y educación musical en el siglo XXI. Revista Electrónica Complutense de Investigación en Educación Musical, 14, 47-59. doi: https://doi.org/10.5209/RECIEM.53380

Burset, S. (2020). Evidencias en el desarrollo de las competencias del ámbito artístico en Dosier Graó, 4, Evidencias científicas para mejorar la práctica docente. Barcelona: Graó. 
Calderón, D., Gustems, J., Calderon, C., y Martín, C. (2017). Character strengths in Spanish music students: An exploratory study. Aloma, 35(2), 59-68.

Calderón, D., Gustems, J., Martín, C., Fuentes, C., y Portela, A. (2020). Emociones en la experiencia artística: claves para el desarrollo educativo y social. Artseduca, 25, 85-101. doi: http:// dx.doi.org/10.6035/Artseduca.2020.25.5

Carrillo, C., Viladot, L., y Pérez, J. (2017). Impacto en la educación musical: una revisión de la literatura científica. Revista Electrónica Complutense de Investigación en Educación Musical, 14, 61-74. doi: https://doi.org/10.5209/RECIEM.54828

Cateura, M. (1992). Por una educación musical en España. Barcelona: P. P. U.

Collelldemont, E. (2008). Retos y dificultades de educar la sensibilidad ante los medios audiovisuales y literarios. Estudios sobre Educación, 14, 45-61.

Domingo, A., y Gómez, V. (2014). La práctica reflexiva: Bases, modelos e instrumentos. Madrid: Narcea.

Dubatti, J. (2012). Teatro, Arte, Ciencias del Arte y Epistemología. Artes, la revista, 18, 145-161. Recuperado de https://dialnet.unirioja.es/servlet/articulo?codigo $=5695736$

Eisner, E. W., y Day, M. D. (2004). Handbook of Research and Policy in Art Education. Nahwah, NJ: National Art Education Association \& Lawrence Erlbaun.

Eurydice (EACEA). (2010). Educación artística y cultural en el contexto escolar en Europa. Madrid: Secretaría General Técnica. Recuperado de http://eacea.ec.europa.eu/Education/eurydice/ documents/ thematic_reports/113ES.pdf

Faure, A., Gustems, J., y Navarro, M. (2020). Producción musical y mercado discográfico: homogeneización entre adolescentes y reto para la educación. Revista Electrónica de LEEME, 45, 69-87. doi: https://doi.org/10.7203/LEEME.45.16625

Gadamer, H. (2000). Elogío de la teoría. Discursos y artículos. Barcelona: Península.

Gardner, H. (1983). Multiple intelligences. Nueva York: Basic Books.

Gardner, H. (2008). Las cinco mentes del futuro. Barcelona: Paidós.

Goleman, D. (1995). Inteligencia emocional. Barcelona: Kairós.

Gombrich, E. H. (1950). The Story of Art. Londres: Phaidon Press.

Gómez Molina, Juan José (Coord.) (2007). La representación de la representación. Madrid: Cátedra.

Gustems, J., Burset, S., y Martín, C. (2018). Educación artística y musical para el siglo XXI. En T. Lleixà, B. Gros, T. Mauri, y J.L. Medina (Coords.), Educación 2018-2020. Retos, tendencias $y$ compromisos, (pp. 51-55). Barcelona: IRE-UB.

Gustems, J., y Calderón, C. (2013). La Investigación en Creatividad: modelos teóricos, evaluación y propuestas para su desarrollo. En J. Gustems (Ed.), Creatividad y Educación Musical: actualizaciones y contextos, (pp. 6-15). Barcelona: Dinsic.

Gustems, J., Calderón, D., y Calderón, C. (2016). Música i desenvolupament cognitiu: una revisió. Temps d'Educació, 50, 87-98.

Holden, H., y Button, S. W. (2006). The teaching of music in the primary school by the nonmusic specialist. The British Journal of Music Education, 23(1), 23-38. doi: http://dx.doi. org/10.1017/S0265051705006728 
Huerta, R., y Domínguez, R. (2016). Las reivindicaciones del profesorado de Educación Artística ante los nuevos obstáculos curriculares; el proyecto «Second Round: Art i Lluita a Secundària». Educación Artística, Revista de Investigación, 7, 10-18. Recuperado de https://dialnet.unirioja.es/servlet/articulo? codigo $=5715304$

Kokotsaki, D., y Hallam, S. (2011). The perceived benefits of participative music making for non-music university students: a comparison with music students. Music Education Research, 13(2), 149-172. doi: https://doi.org/10.1080/14613808.2011.577768

López García, N. J., y De Moya Martínez, M.V. (2015). La música en las escuelas europeas. Albacete: LiberLibro.

López, N. J., y De Moya, M. V. (2017). Documentos clave de la Unión Europea sobre educación musical en las enseñanzas obligatorias. Revista Electrónica Complutense de Investigación en Educación Musical, 14, 171-186. doi: https://doi.org/10.5209/RECIEM.52409

Marín Viadel, R. (coord.) (2003). Didáctica de la Educación Artística. Madrid: Pearson Educación.

Marín Viadel, R. (2011). La Investigación en Educación Artística. Educatio Siglo XXI, 29(1), 211-230. Recuperado de https://revistas.um.es/educatio/article/view/119951

Martínez Luna, S. (2017). 'Ni/ni': 'entrelugares'del arte y la educación. Ni arte ni educación. Una experiencia en la que lo pedagógico vertebra lo artístico. Madrid: Catarata.

Orden ECI/3858/2007, de 27 de diciembre, por la que se establecen los requisitos para la verificación de los títulos universitarios oficiales que habiliten para el ejercicio de las profesiones de Profesor de Educación Secundaria Obligatoria y Bachillerato, Formación Profesional y Enseñanzas de Idiomas. Boletín Oficial del Estado, 312, de 29 de diciembre de 2007. Recuperado de https://www.boe.es/buscar/act.php?id=BOEA-2007-22450

Perrenoud, P. (2012). Cuando la escuela pretende preparar para la vida. ¿Desarrollar competencias o enseñar otros saberes? Barcelona: Graó.

Piaget, J. (1979). La epistemología de las relaciones interdisciplinares. En L. Apostel, G. Berger, A. Briggs y G. Michaud (Eds.), Interdisciplinariedad. Problemas de la enseñanza y de la investigación en las Universidades, (pp. 153-171). México: Asociación Nacional de Universidades e Institutos de Enseñanza Superior.

Pozo, J. I., Bautista, A., y Torrado, J. A. (2008). El aprendizaje y la enseñanza de la interpretación musical: cambiando las concepciones y las prácticas, Cultura y Educación, 20(1), 5-15, doi: 10.1174/113564008783781495

Prieto, R. (2001). El perfil del maestro de primaria especialista en educación musical. Revista Interuniversitaria de Formación del Profesorado, 40, 175-186. Recuperado de https:// dialnet.unirioja.es/servlet/articulo? codigo $=118097$

Sánchez, D. (coord.). (2013). Epistemología de las artes la transformación del proceso artístico en el mundo contemporáneo. Buenos Aires: Editorial de la Universidad de la Plata.

Serrano, J. A., Lera, A., y Contreras, O. (2007). Maestros generalistas vs especialistas. Claves y discrepancias en la reforma de la formación inicial de los maestros de primaria. 
Revista de Educación, 344, 533-555. Recuperado de https://dialnet.unirioja.es/servlet/ articulo? codigo $=2347119$

Spychiger, M., Patry, J., Lauper, G., Zimmerman, E., y Weber, E. (1993). Does more music teaching lead to a better social climate, En R. Olechowski y G. Svik (Eds), Experimental research in teaching and learning, (pp. 322-336). Berna: Peter Lang.

Unesco. (1998). Informe mundial sobre educación. París: Ediciones Unesco.

Unesco. (2006). Hoja de Ruta para la Educación Artística. Lisboa: Unesco.

Willems, E. (1989). El valor humano de la educación musical. México: Paidós.

Zulauf, M. (1993). Three year experiment in extended music teaching in Switzerland: the different effects observed in a group of French speaking pupils. Bulletin of the Council for Research in Music Education, 119, 111-121. Recuperado de https://www.jstor.org/stable/i40013235 